\title{
Copper Oxide Nanoparticles-Catalyzed Aziridine Ring Opening with Diaryl Diselenides Under lonic Liquid as Reaction Medium
}

\author{
Antonio Luiz Braga ${ }^{1}$, Syed M. Salman, ${ }^{\star 2}$ Sayyar Muhamamd, ${ }^{2}$ Oscar E. D. \\ Rodrigues, ${ }^{3}$ Luciano Dornelles, ${ }^{3}$ Ricardo S. Schwab ${ }^{3}$ \\ ${ }^{1}$ Departamento de Química, Universidade Federal de Santa Catarina, Florianópolis, SC, 88040-970, Brazil \\ ${ }^{2}$ Department of Chemistry, Islamia College University, Peshawar, KPK, Pakistan \\ ${ }^{3}$ Departamento de Química, Universidade Federal de Santa Maria, Santa Maria, RS, 97105- 900, Brazil
}

*salmanchemist80@yahoo.com

Keywords: Aziridine ring opening, chiral $\beta$-seleno amine, CuO nanopowder catalyst

\section{INTRODUCTION}

The development of new methods for the introduction of selenium-containing groups into organic molecules remains a significant challenge. ${ }^{1}$ Moreover, chiral selenide- and diselenides containing ligands offer attractive and practical options in the development of asymmetric transformations. In this context, a straightforward synthesis of a new set of chiral $\beta$-seleno amine through a stereoselective aziridine ring opening with selenium nucleophiles, generated by reducing agents such as $\mathrm{NaBH}_{4}, \mathrm{LiBHEt}_{3}$, zinc or indium salts have been described by our group ${ }^{2}$.

We herein report an ecofriendly procedure for the synthesis of chiral $\beta$-seleno amine under mild conditions, using selenium nucleophile generated by base in the presence of $\mathrm{CuO}$ nanopowder as a catalyst in ionic liquid $\mathrm{BMIM}\left[\mathrm{BF}_{4}\right]$ as solvent.

\section{RESULTS AND DISCUSSION}

In order to evaluate the performance of the aziridine ring-opening reaction, we firstly used diphenyl diselenide (1.0 equiv) and Ts protected aziridines (2.0 equiv) derived from $L$-phenylalanine as standard reagent in the presence of $5 \mathrm{~mol} \%$ of $\mathrm{CuO}$ nanopowder and $\mathrm{KOH}$ (2.0 equiv) as a base in ionic liquid $(1.0 \mathrm{~mL})$ for $60 \mathrm{~min}$ under $80{ }^{\circ} \mathrm{C}$ (Table 1 ).

Table 1. Screening of reaction conditions

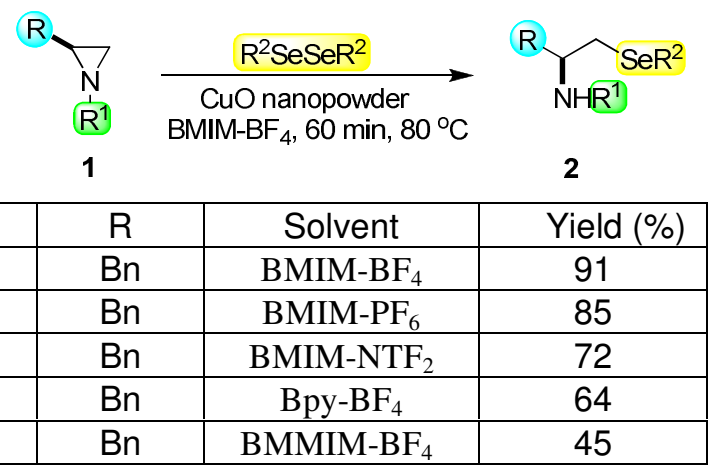

With the best conditions in hands, the scope and applications of this new methodology were examined and the products are shown below.
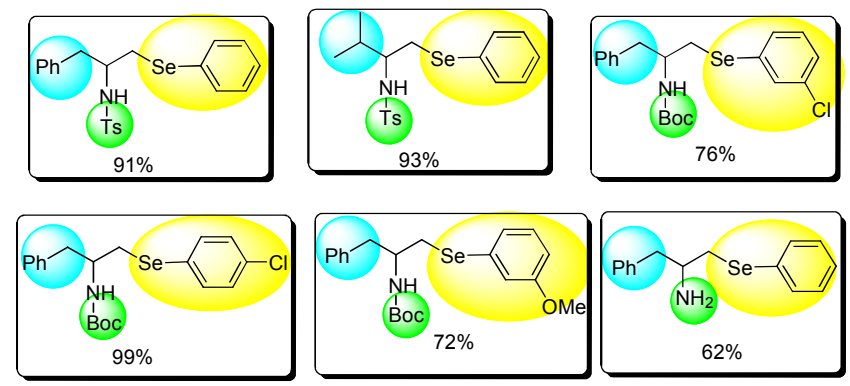

\section{CONCLUSION}

In summary, we have described a practical and concise synthesis of structurally diverse chiral $\beta$ seleno amines via ring opening reaction of protected and unprotected aziridines in ionic liquid by using copper nanoparticles as catalyst. By using this methodology, we recycled catalyst and ionic liquids, which were reused in the next four runs.

\section{ACKNOWLEDGEMENTS}

Higher Education Commission of Pakistan (HEC), CNPQ, CAPES, and FAPERGS.

\section{REFERENCES}

1. Braga, A. L.; Lüdtke, D. S.; Vargas, F.; Braga, R. C. Synlett 2006, 1453.

2. (a) Braga, A. L.; Lüdtke, D. S.; Paixão, M. W.; Rodrigues, O. E. D. Org. Lett. 2003, 5, 2635; (b) Braga, A. L.; Paixão, M. W.; Marin, G. Synlett 2005, 1675; (c) Braga, A. L.; Schneider, P. H.; Paixão, M. W.; Deobald, A. M.; Peppe, C.; Bottega, D. P. J. Org. Chem. 2006, 71, 4305. (d) Braga, A. L.; Schwab, R. S.; Alberto, E. E.; Salman, S. M. Vargas, J.; Azeredo, J. B. Tetrahedron Lett. 2009, 50, 2309. 